\section{La melioidosis: una enfermedad emergente en las Américas}

La melioidosis es una enfermedad de origen bacteriano de posible desenlace fatal, propia de zonas tropicales y subtropicales. Es posible que la falta del adecuado respaldo técnico y la insuficiente experiencia profesional para diagnosticar esta infección, especialmente en zonas rurales donde es más frecuente, haya provocado su desconocimiento y subdiagnóstico en América Latina y el Caribe.

En este artículo, los autores hacen una interesante y oportuna revisión sobre esta enfermedad emergente y ofrecen una visión muy bien documentada de sus principales particularidades etiológicas, clínicas y epidemiológicas, con especial referencia a la salud en la Región de las Américas. El conocimiento de esta infección por parte de las autoridades y profesionales de la salud pública es una necesidad impostergable y debe contribuir a su adecuado y oportuno control.

La melioidosis se adquiere por la exposición ambiental al bacilo gramnegativo Burkholderia pseudomallei, anteriormente denominado Pseudomonas pseudomallei. La infección se produce por la inhalación, inoculación y, posiblemente, por la ingestión de este microorganismo, presente en suelos húmedos $\mathrm{y}$ aguas superficiales contaminados. Los grupos en mayor riesgo de adquirir esta enfermedad son los obreros agrícolas - especialmente los dedicados al cultivo del arroz-, los indígenas y los habitantes rurales de zonas tropicales. El período pico de la infección aguda corresponde a la época de lluvias, especialmente cuando estas son intensas.

Las manifestaciones clínicas de la melioidosis son muy diversas y pueden variar desde la presentación asintomática y la enfermedad subaguda con supuración y abscesos, hasta la septicemia con neumonía y el fallo sistémico de múltiples órganos. Los síntomas pueden demorar en aparecer meses y a veces años. El riesgo de septicemia y de otras formas graves de esta enfermedad es mayor en pacientes con diabetes, insuficiencia renal crónica, hepatitis alcohólica o afecciones respiratorias crónicas.

Es frecuente que los casos de melioidosis no reciban un diagnóstico oportuno. Esto puede deberse a la falta de experiencia profesional directa con esta afección, a la presentación tardía de la enfermedad y a la ausencia de características distintivas de su forma aguda, entre otras causas. Además, es frecuente que en las muestras biológicas se encuentren otras bacterias patógenas que pueden enmascarar el diagnóstico microbiológico. Las pruebas serológicas no tienen la sensibilidad y la especificidad requeridas y la reacción en cadena de la polimerasa es con frecuencia inadecuada por la presencia de inhibidores tisulares de las enzimas necesarias. Incluso en laboratorios bien establecidos, el diagnóstico puede ser equívoco hasta poder familiarizarse mejor con las particularidades específicas de B. pseudomallei, entre ellas su inusual comportamiento ante la tinción de Gram, su patrón de resistencia a antibióticos y su olor característico a tierra. Las investigaciones actuales relacionadas con la bioseguridad contribuirán a mejorar el diagnóstico, el tratamiento y la prevención de la melioidosis.

La mayor parte de las personas detectadas con melioidosis en los Estados Unidos de América han sido veteranos de la guerra de Vietnam, ocurrida a finales de la década de 1960. También se ha informado de posibles casos en Ecuador, Brasil y algunos países de América Central. Esta infección se ha diagnosticado también en refugiados por desastres naturales ocurridos en América Central.

El patrón epidemiológico de la melioidosis en las Américas puede contribuir a obtener una mejor caracterización de esta enfermedad infecciosa. La tipificación molecular de varios aislamientos clínicos obtenidos de casos recientes procedentes del nordeste brasileño contradice la hipótesis de la introducción y rápida diseminación de una sola cepa.

La impresión de que la melioidosis se está expandiendo en América Latina puede ser el resultado de una mejoría en los métodos de diagnóstico disponibles y de prestar una mayor atención a esta enfermedad. No obstante, se requiere de una mayor conciencia y preocupación por parte de las autoridades nacionales y regionales del sector salud, así como del desarrollo de métodos de diagnóstico más eficaces, para lograr un mejor control de la melioidosis en las Américas y el mundo. (Inglis TJJ, Rolim DB, de Queiroz Sousa A. Melioidosis in the Americas. Am J Trop Med Hyg. 2006;75(5):947-54.) 